\title{
ESPECIAÇÃO DE COBRE E CHUMBO EM SEDIMENTO DO RIO TUBARÃO (SC) PELO MÉTODO TESSIER
}

Maria Carminati Lima, Maria Bertilia O. Giacomelli, Volnei Stüpp, Fernanda D. Roberge

Universidade do Sul de Santa Catarina, Av. José Acácio Moreira, 787, 8704-900 Tubarão - SC

Pilar Bermejo Barrera*

Universidade de Santiago de Compostela, Av. de las Ciencias, s/n Campus Sur, E-15706, Santiago de Compostela - Espanha

Recebido em 28/7/00; aceito em 18/5/01

\begin{abstract}
SPECIATION ANALYSIS OF COPPER AND LEAD IN TUBARÃO RIVER SEDIMENT USING THE TESSIER SEQUENTIAL EXTRACTION PROCEDURE. The sequential extraction procedure proposed by Tessier and total digestion were applied for the analysis of sediment samples from Tubarão River. The recoveries were between 93.5 and $102.5 \%$ for $\mathrm{Cu}$ and 99.2 and $111 \%$ for $\mathrm{Pb}$. The precision was tipically better than $6 \%$ for $\mathrm{Cu}$ and $3 \%$ for $\mathrm{Pb}$. Comparison of the values obtained for the total digest with the sum of the extracted fractions showed that there were no significant losses in the extraction steps so that the method can be used for the monitoring availability and mobility of these analytes. According to ten points of sampling, was possible to determined the average of labiles phases (fractions 1 and 4 ) for $\mathrm{Pb}$ and $\mathrm{Cu}: 33.70 \%$ and $18.18 \%$, respectively; and the inert phases (fraction 5residual): $66.30 \%$ for $\mathrm{Pb}$ and $81.82 \%$ for $\mathrm{Cu}$.
\end{abstract}

Keywords: Tessier; speciation; river sediment; copper and lead.

\section{INTRODUÇÃO}

A Bacia Hidrográfica do Rio Tubarão e Sistema Lagunar encontram-se na Região Sul do Estado de Santa Catarina e pertencem à vertente de drenagem Atlântica, fazendo limite com a vertente do interior através da Serra Geral, tendo as seguintes coordenadas geográficas como limites: $27^{\circ} 48^{\prime} 00^{\prime \prime}$ ' de latitude norte, $28^{\circ} 48^{\prime} 08^{\prime \prime}$ de latitude sul, $48^{\circ} 38^{\prime} 18^{\prime}$ ' de longitude leste e $48^{\circ} 31^{\prime} 48^{\prime}$ ' de longitude oeste. É a mais expressiva bacia hidrográfica da Região Sul de Santa Catarina; engloba 19 dos 21 municípios da região e tem uma área de $5923 \mathrm{~km}^{2}$ aproximadamente ${ }^{1}$.

A Bacia Hidrográfica Sul Catarinense é constituída pelas bacias dos Rios Tubarão e D’Una. O Rio Tubarão passa a assim denominar-se após a confluência dos Rios Bonito e Rocinha que têm origem na encosta da Serra Geral. Ambos drenam regiões de mineração logo após suas nascentes, onde ocorrem extensas áreas de extração e depósitos de rejeitos do beneficiamento do carvão. O Rio Tubarão percorre uma distância de $120 \mathrm{~km}$, desembocando na Lagoa de Santo Antônio dos Anjos, no município de Laguna, local de intensa atividade pesqueira e turístical, ${ }^{1}$.

As principais fontes poluidoras da região são: efluentes de resíduos de mineração e beneficiamento do carvão, fecularias, vinícolas, olarias, cerâmicas, suinocultura, indústrias alimentícias, termelétrica, extração de fluorita, além de esgotos domésti$\cos ^{1}$. Notadamente, os rejeitos da extração do carvão e seu beneficiamento contribuem para o comprometimento das águas do Rio Tubarão em quase toda sua extensão ${ }^{3}$.

As águas da bacia servem como fonte para o abastecimento público de pelo menos seis municípios, além de serem usadas também para abastecimento industrial, irrigação e recreação.

As legislações ambientais vigentes levam em conta em termos de qualidade das águas, apenas níveis de concentração de substâncias, ou cátions e ânions, determinados nas próprias águas. Entretanto, estas informações são de escasso valor, devido a alterações a que estão sujeitas, sobretudo considerando

e-mails: mlima@unisul.rct-sc.br; qn1956@usc.es*; bertilia@unisul.rct-sc.br a diluição no meio. Os limites de concentração têm interesse prático para localizar pontos de maior risco a curto prazo e delimitar focos de produção de contaminação $0^{4,5}$.

Nos últimos anos, tem aumentado a investigação sobre metais presentes nos sedimentos, não mais como um reservatório ou ambiente de deposição de espécies químicas, mas sim como um compartimento aquático ativo que desempenha um papel fundamental na redistribuição dessas espécies à biota aquática ${ }^{6}$.

Com base nestas informações, a investigação do sedimento do Rio Tubarão é uma questão de sobrevivência, tanto do ponto de vista dos organismos aquáticos como fonte de abastecimento de água.

Os sedimentos já foram considerados um compartimento de acumulação para espécies contaminantes. Alguns pesquisadores $^{7,8}$ revelam, contudo, que estas espécies são geralmente liberadas do leito dos sedimentos, podendo contaminar a água e, através deste fluido, outros sistemas ambientais que, mesmo muito tempo após as fontes ativas de poluição terem sido eliminadas, podem ser atingidos. Em conseqüência, a contaminação de sedimentos é um grande problema de poluição ambiental em todo o mundo.

Segundo Scorzelli et $\mathrm{al}^{9}$, uma das conseqüências de um crescimento industrial desordenado é a grande liberação de íons e/ ou compostos metálicos em micro ambientes, causando danos à vida animal e vegetal. Desta forma, apesar dos bens minerais metálicos contribuírem para o desenvolvimento industrial e tecnológico, estes também constituem fontes poluidoras do meio ambiente, podendo provocar impactos ambientais, em alguns casos, bastante relevantes.

Os sedimentos estão constituídos por diferentes substratos geoquímicos dos quais os mais importantes são aqueles que detêm a capacidade de reter e concentrar elementos traço. Estes substratos possuem alta superfície específica e alta capacidade de troca catiônica ${ }^{10}$. A característica fundamental desses materiais é que são termodinamicamente instáveis, sendo constituídos por substâncias amorfas ou pouco cristalinas ${ }^{11}$.

Diferentes autores estabelecem listas de materiais hierarquizados em função de sua capacidade para reter metais traço. Assim, Förstner ${ }^{12}$ indica que os óxidos de manganês têm maior capacidade que os óxidos de ferro e estes, que as argilas. 
Esta classificação realiza-se com base em estudos de extrações seletivas. Horowittz e Elrick ${ }^{13}$ dão uma lista ligeiramente diferente, baseada em valores dos coeficientes de correlação entre os distintos substratos e os metais-traço, na qual os óxidos de ferro têm maior capacidade de concentração de metais que os óxidos de manganês. As diferenças obtidas por ambos os autores se devem à combinação de fatores que incluem, entre outros, a procedência dos sedimentos utilizados e as fontes empregadas para definir os distintos substratos geoquímicos.

Os sedimentos são reconhecidos como transportadores e possíveis fontes de contaminação dos sistemas aquáticos, já que tais materiais podem liberar contaminantes, como consequiência de trocas ambientais ou das condições físico-químicas ( $\mathrm{pH}$, oxigênio dissolvido, ação de bactérias, entre outros) do sistema, afetando a qualidade da água e originando bioacumulação e trocas de transferência na cadeia trófica ${ }^{10,14}$. Além disso, os constituintes do sedimento podem degradar-se ou reagir com outros, dando formas solúveis ou potencialmente mais tóxicas, como a conversão de arsenopirita em óxidos de ferro associados a arsênio ${ }^{10}$.

Os metais não são naturalmente degradados, nem mesmo permanentemente fixados pelos sedimentos, podendo assim serem redispostos à coluna d'agua através de alterações do meio.

Assim sendo, a determinação de metais traço em sedimentos nos permite detectar o acréscimo de contaminação que a água está sujeita, bem como aos organismos bentônicos.

Dentro das suas limitações, o uso de extrações seqüenciais (especiação) resulta em informações sobre forma química da origem, forma de ocorrência, disponibilidade física, química e biológica, mobilização e transporte de metais em sedimento.

A especiação química é definida como um processo de identificação e quantificação das diferentes espécies, formas ou fases presentes no material ou na descrição dos mesmos ${ }^{15}$. Diferentes métodos de especiação são propostos na literatura, dentre eles destacam-se Tessier ${ }^{16}$, Meguellati ${ }^{17}$ e Community Bureau of Reference (BCR) ${ }^{18,19}$, entre outros. Os procedimentos utilizados têm certas semelhanças, embora apresentem características peculiares. Entretanto, estudos têm demonstrado que as informações obtidas são praticamente concordantes ${ }^{5,20}$. Na extração seqüencial, a amostra é tratada com uma sucessão de regentes chamados extratores, com a intenção específica de dissolver as diferentes fases dos sedimentos. Cada extrator seqüencialmente adicionado tem uma ação química mais drástica e de diferente natureza que a anterior.

Os extratores parciais podem ser classificados como: concentrados de eletrólitos inertes, ácidos fracos, agentes redutores, agentes complexantes, agentes oxidantes e ácidos minerais fortes.
As frações da especiação são definidas operacionalmente pelas propriedades químicas dos extratores usados, daí uma das limitações intrínsecas do método.

Elementos como o $\mathrm{Zn}, \mathrm{Fe}$ e $\mathrm{Mn}$ em extratos de sedimentos, obtidos pela extração seqüencial, são freqüentemente determinados empregando-se a técnica de espectrometria de absorção atômica com chama (FAAS). Entretanto, a detecção de elementos como $\mathrm{Cu}, \mathrm{Cd}, \mathrm{Pb}$, entre outros, pode requerer uma técnica mais sensível ${ }^{15}$. Neste caso, a espectrometria de absorção atômica com atomização eletrotérmica em forno de grafite (ETAAS) é, sem dúvida, uma das mais adequadas, precisas e confiáveis.

Neste estudo, escolheu-se inicialmente a determinação de $\mathrm{Cu}$ e $\mathrm{Pb}$ pelas principais características da região, destacando-se a mineração do carvão que apresenta, além de outros metais, as espécies de interesse, além da confluência de pequenos rios que percorrem regiões produtoras de frutas, em especial uvas, com uso freqüente de pesticidas à base de $\mathrm{Cu}^{21,22}$.

O objetivo do presente trabalho é determinar as diferentes formas em que os metais $\mathrm{Cu}$ e $\mathrm{Pb}$ podem estar associados no sedimento do Rio Tubarão, aplicando o método da extração seqüencial proposto por Tessier et al., com modificações. Com isso, estimar o grau da contaminação deste compartimento ambiental através da concentração total encontrada, bem como da distribuição entre as fases consideradas lábeis e inertes dos sedimentos.

\section{PARTE EXPERIMENTAL}

Dez pontos de amostragem foram estrategicamente selecionados. O mapa da região em estudo é mostrado na Figura 1, e identifica os locais de coleta.

O ponto 1 foi estabelecido na nascente do Rio Bonito e o ponto 2, na nascente do Rio Rocinha. Os pontos 3 e 4 correspondem aos Rios Bonito e Rocinha antes da confluência, na cidade de Lauro Müller. Destaca-se que nestes dois últimos pontos têm início a região da exploração de carvão. O ponto 5 foi definido após a cidade de Lauro Müller, localidade completamente afetada pelos rejeitos da mineração. O ponto 6 foi estabelecido após a cidade de Orleans. O ponto 7 foi determinado após a confluência do Rio Palmeiras, destacando-se que próximo à sua nascente é efetuada a exploração de carvão. $\mathrm{O}$ ponto 8 foi definido após a junção do Rio Braço do Norte que traz consigo elevados níveis de matéria orgânica ${ }^{1}$ intensificados pelas atividades agro-industriais da região, sobretudo pela criação de suínos e preparação de seus derivados. O ponto 9 foi estabelecido antes da cidade de Tubarão, no local onde a Companhia de Águas e Saneamento - CASAN coleta a água para tratamento e distribuição à população. $\mathrm{O}$ ponto 10 foi determinado

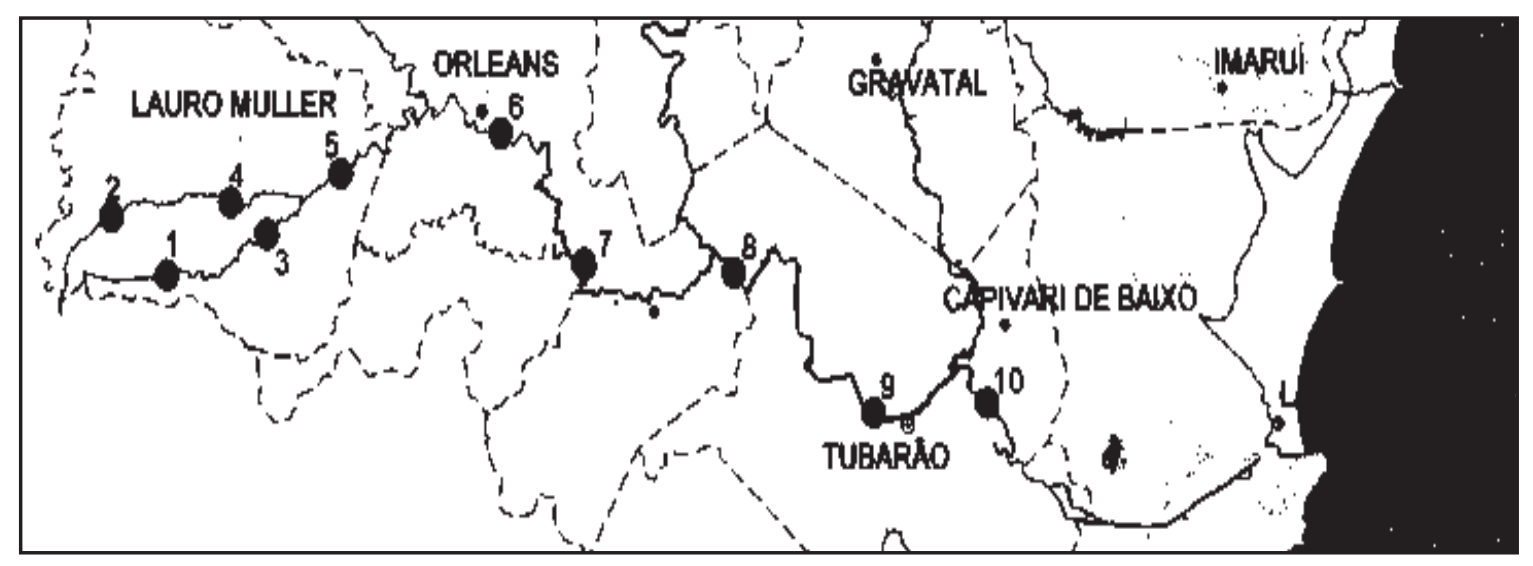

Figura 1. Mapa da região representando os dez pontos de coleta. 
após a confluência do Rio Capivari com o canal da empresa que gera energia elétrica através do uso do carvão.

Os diversos pontos de amostragem foram distribuídos, a fim de que pudessem ser avaliadas as atividades de mineração, dos municípios e dos afluentes que deságuam no Rio Tubarão.

As amostras foram coletadas entre 1,5-2,0 m de distância da margem e à uma profundidade de $10-15 \mathrm{~cm}$, utilizando-se um coletor de PVC manufaturado no laboratório ${ }^{3}$. Foram acondicionadas em sacos plásticos e transportadas sob refrigeração para imediata peneiração a úmido, utilizando-se água da própria coleta. Neste processo, foi empregada peneira de nylon de $63 \mu \mathrm{m}$ de abertura de malha, uma vez que muitos estudos têm demonstrado que as concentrações mais elevadas de metais ocorrem nas frações mais finas do sedimento ${ }^{23}$.

\section{Preparação das Amostras}

As amostras peneiradas foram secadas em estufa com circulação de ar à temperatura de $40^{\circ} \mathrm{C}$. Logo após, maceradas em gral de porcelana e acondicionadas em recipientes de polietileno. Foram pesados $1,0 \mathrm{~g}$ de cada amostra em tubo de centrífuga e iniciado o processo de extração, conforme mostra o esquema da Figura 2. Foi utilizado o método de extração proposto por Tessier $^{16}$ et al., modificado com substituição do extrator 1 , de $\mathrm{MgCl}_{2} 1 \mathrm{~mol} \mathrm{~L}^{-1}$ e pH 7, para NaOAc 1 mol L-1, $\mathrm{pH} \mathrm{8,2.} \mathrm{As}$ extrações seletivas foram realizadas em tubos de centrífuga para minimizar as perdas do material sólido. A agitação foi efetuada com agitador de Wagner. Entre cada extração sucessiva, a separação foi feita em uma centrífuga à $3900 \mathrm{rpm}$, durante 30 minutos. O sobrenadante foi retirado com micropipeta para ser analisado por ETAAS. O resíduo foi lavado com $8 \mathrm{~mL}$ de água deionizada ultra pura $\left(18 \mathrm{M} \Omega . \mathrm{cm}^{-1}\right.$ de resistividade específica), e depois de centrifugado a água foi descartada e o resíduo submetido à extração seguinte. Durante todo o processo de extração foi sempre processado um controle (branco) das amostras. Nas etapas de aquecimento, a temperatura foi controlada utilizando-se um banho-maria Dubnoff. Ao resíduo final, após seco e pesado em um tubo digestor PTFE, foi adicionado $0,5 \mathrm{~mL}$ de água deionizada, $3 \mathrm{~mL}$ de $\mathrm{HCl}$ e $1 \mathrm{~mL}$ de $\mathrm{HNO}_{3}$ para digestão ácida em forno microondas, seguindo as condições operacionais resumidas na Tabela 1, completando-se o volume para $25 \mathrm{~mL}$ com água deionizada.

Também procedeu-se a digestão total das mesmas amostras de sedimento utilizadas para a extração seqüencial. Foi pesado 0,5 g de cada amostra, em triplicata, em frasco digestor (PTFE), adicionados $15 \mathrm{~mL}$ de $\mathrm{HF}$ e posteriormente submetidas a um

Tabela 1. Programa empregado no forno microondas para obtenção da fração 5 e digestão total do sedimento.

\begin{tabular}{ccc}
\hline Etapas & Tempo $(\min )$. & Potência $(\mathrm{W})$ \\
1 & 1 & 850 \\
2 & 4 & 000 \\
3 & 1 & 850 \\
4 & 4 & 000 \\
5 & 1 & 850 \\
6 & 4 & 000 \\
7 & 1 & 850 \\
\hline
\end{tabular}

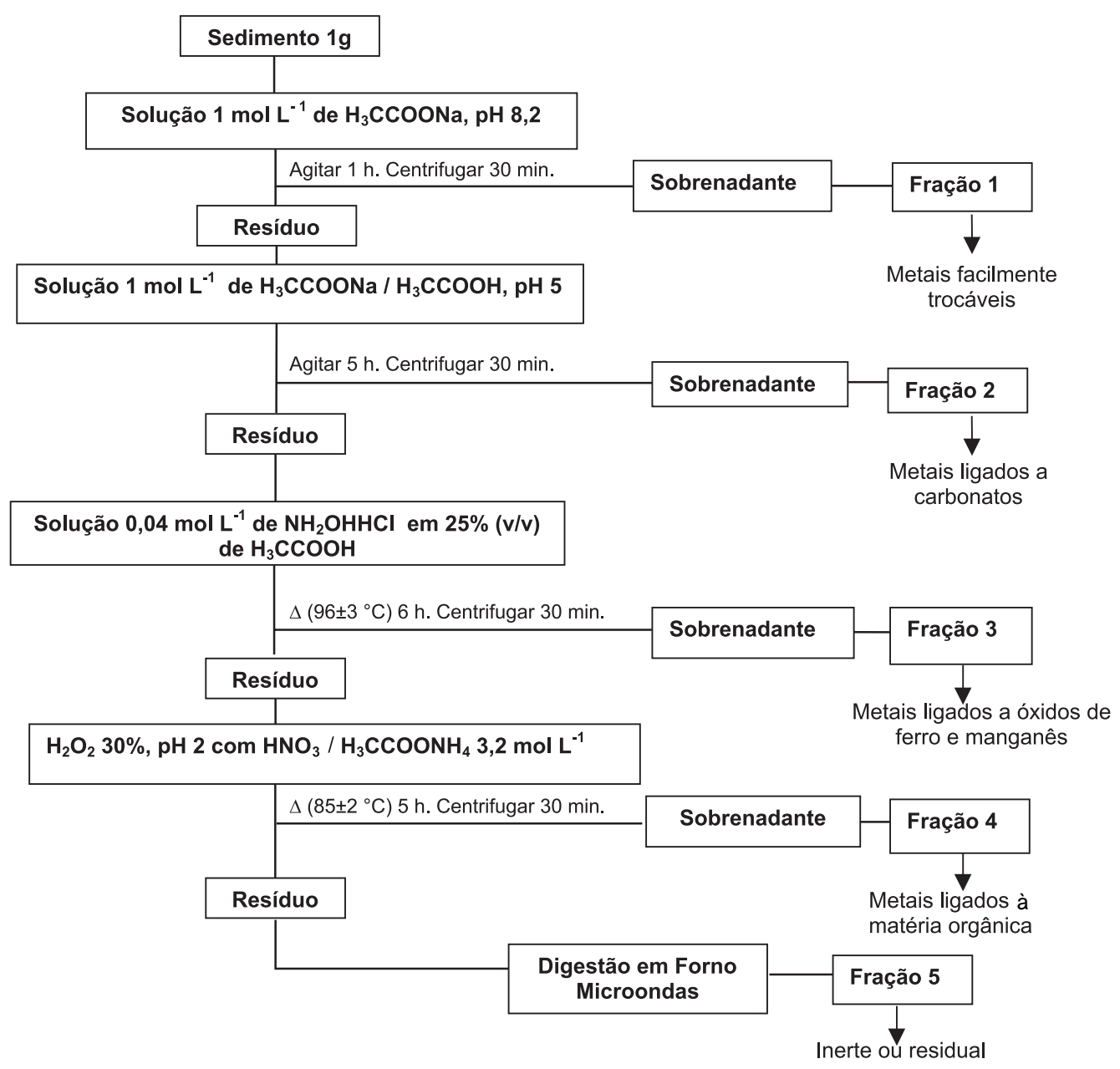

Figura 2. Esquema do método Tessier et al., modificado, aplicado ao sedimento do Rio Tubarão. 
aquecimento brando até a evaporação total. Em seguida, foram acrescentados $4 \mathrm{~mL}$ de $\mathrm{HCl}$ e $3 \mathrm{~mL}$ de $\mathrm{HNO}_{3}$, sendo então conduzido ao forno microondas, seguindo as condições operacionais já descritas na Tabela 1. Após a digestão total, o volume foi completado para $100,00 \mathrm{~mL}$ com água deionizada.

\section{Reagentes e Soluções}

A limpeza de todos os materiais utilizados foi efetuada com solução 5\% de detergente alcalino Extran (Merck), posteriormente lavados com água deionizada e em seguida deixados em repouso, no mínimo por 24 horas, em solução $10 \%$ v/v de $\mathrm{HNO}_{3}$ P.A. Finalmente foi enxaguado com água deionizada.

No preparo de todas as soluções empregou-se água deioni-

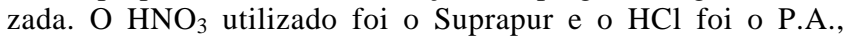
ambos Merck.

As soluções padrão de nitrato de chumbo e nitrato de cobre, ambas $1000 \mathrm{mg} \mathrm{L}^{-1}$ foram preparadas a partir de ampolas Titrisol (Merck), de acordo com as orientações do fabricante.

Como modificador químico de matriz, foi utilizada uma mistura 1:1 de $\mathrm{Pd}\left(\mathrm{NO}_{3}\right)_{2} 0,3 \%+\mathrm{Mg}\left(\mathrm{NO}_{3}\right)_{2} 0,2 \%$, sendo que a solução de $\mathrm{Pd}\left(\mathrm{NO}_{3}\right)_{2}$ foi preparada dissolvendo-se $300 \mathrm{mg}$ de pó de paládio de pureza 99,999\% (Merck) em $1 \mathrm{~mL}$ de $\mathrm{HNO}_{3}$ concentrado e diluído para 100,00 mL com água. Peróxido de hidrogênio $30 \% \mathrm{p} / \mathrm{v}$, ácido acético glacial $99,8 \%$, cloreto de hidroxilamônio $99 \%$ e acetato de amônio, todos Merck, e acetato de sódio $99,7 \%$ (Mallinckrodt $\mathrm{AR}^{\mathrm{R}}$ ) foram os reagentes utilizados no método de extração seqüencial.

\section{Instrumentação}

As determinações de $\mathrm{Cu}$ e $\mathrm{Pb}$ foram realizadas em um espectrômetro de absorção atômica com atomização eletrotérmica com forno de grafite GTA 110 (Varian, modelo SpectrAA 220), equipado com corretor de fundo Zeeman e amostrador automático. O sistema de aquisição de dados foi gerenciado por microcomputador em ambiente Windows e, como fonte de radiação, foram empregadas lâmpadas de cátodo oco de $\mathrm{Cu}$ e $\mathrm{Pb}$, operando em 7 e 9 mA e comprimentos de onda 327,4 e 283,3 $\mathrm{nm}$, respectivamente, ambas com abertura de fenda de $0,5 \mathrm{~nm}$. Foram utilizados tubos de grafite Varian (Part No 97/506 991) revestidos piroliticamente e plataformas de L'Vov também Varian ( $\mathrm{N}^{\mathrm{o}}$ VII/113/78501).

Para monitorar os sinais analíticos, foi utilizado o algorítmo de calibração linear origin com o modo de medida em pront área. Argônio de pureza $99,996 \%$ foi utilizado como gás de proteção.

Tabela 2. Programa de aquecimento para a determinação de $\mathrm{Cu}$.

\begin{tabular}{|c|c|c|c|c|c|}
\hline Etapas $\mathrm{T}$ & $\begin{array}{c}\text { Temperatura } \\
\left({ }^{\circ} \mathrm{C}\right)\end{array}$ & $\begin{array}{l}\text { Tempo } \\
\text { (s) }\end{array}$ & $\begin{array}{l}\text { Fluxo Gás } \\
\left(\mathrm{L} \min ^{-1}\right)\end{array}$ & $\begin{array}{r}\text { Tipo } \\
\text { Gás }\end{array}$ & $\begin{array}{c}\text { Comando } \\
\text { Leitura }\end{array}$ \\
\hline 1 & 300 & 30 & 3,0 & Argônio & Não \\
\hline 2 & 300 & 60 & 3,0 & Argônio & Não \\
\hline 3 & * & 10 & 3,0 & Argônio & Não \\
\hline 4 & $*$ & 10 & 3,0 & Argônio & Não \\
\hline 5 & $*$ & 2 & 0,0 & Argônio & Não \\
\hline 6 & $* *$ & 1 & 0,0 & Argônio & Sim \\
\hline 7 & $* *$ & 2 & 0,0 & Argônio & Sim \\
\hline 8 & $* *$ & 2 & 3,0 & Argônio & Não \\
\hline 9 & 40 & 40 & 3,0 & Argônio & Não \\
\hline$* 1800^{\circ} \mathrm{C}$ & e $* * 27$ & $700^{\circ} \mathrm{C}$ & fração 1 & & \\
\hline$* 1800^{\circ} \mathrm{C}$ & e $* * 27$ & $700^{\circ} \mathrm{C}$ & fração 2 & & \\
\hline$* 1200^{\circ} \mathrm{C}$ & e $* * 26$ & $500^{\circ} \mathrm{C}$ & fração 3 & & \\
\hline$* 1700^{\circ} \mathrm{C}$ & e $* * 27$ & $700^{\circ} \mathrm{C}$ & fração 4 & & \\
\hline$* 1100^{\circ} \mathrm{C}$ & $\mathrm{e} * * 27$ & $700^{\circ} \mathrm{C}$ & fração 5 & & \\
\hline
\end{tabular}

\section{Otimização das Temperaturas de Pirólise e Atomização}

Para a obtenção das curvas de pirólise, manteve-se constante a temperatura de atomização de $2300{ }^{\circ} \mathrm{C}$ e $2400{ }^{\circ} \mathrm{C}$ para $\mathrm{Cu}$ e $\mathrm{Pb}$, respectivamente. Tendo otimizadas as temperaturas de pirólise, foram estudadas as temperaturas de atomização nas diferentes frações. Em alguns casos, quando necessário, a fração foi diluída com o próprio extrator. Em outros, adicionou-se uma concentração de $60 \mu \mathrm{g} \mathrm{L}^{-1}$ de $\mathrm{Cu}$ ou $\mathrm{Pb}$, para uma melhor otimização.

Os programas de temperaturas otimizados para as determinações de $\mathrm{Cu}$ e $\mathrm{Pb}$ estão apresentados nas Tabelas 2 e 3, respectivamente. Foram respeitadas as condições Forno Plataforma de Temperatura Estabilizada (STPF) em todas as determinações ${ }^{24}$.

\section{RESULTADOS}

\section{Curvas de Pirólise e Atomização}

Na Figura 3, estão apresentadas as curvas de pirólise e atomização para $\mathrm{Cu}$ e $\mathrm{Pb}$ em cada uma das frações.

Observou-se que foram obtidas temperaturas relativamente altas para ambas as espécies de interesse, sobretudo na etapa de pirólise. Isto possivelmente se deve ao uso de extratores com caráter salino, pouco diluídos, nas primeiras frações. Recomenda-se atenção na programação do tempo de secagem. Para esta determinação, acompanhou-se visualmente a evolução da gota da amostra dentro do tubo. Esta observação permitiu-nos verificar que não ocorreu crepitação nesta etapa, não ocasionando perdas da amostra.

Tendo-se otimizado as temperaturas de pirólise e atomização, procedeu-se também a otimização da quantidade do modificador, conforme a Tabela 4.

Para a escolha da quantidade de modificador, principalmente para $\mathrm{Pb}$, foi sempre levado em consideração, além da absorvância, o melhor perfil do sinal analítico. As Figuras 4 e 5 apresentam os sinais analíticos obtidos para $\mathrm{Cu}$ e $\mathrm{Pb}$ após as otimizações descritas acima.

\section{Curvas de Calibração}

Após as otimizações realizadas, fez-se o estudo das curvas de calibração para cada fração, preparando-se soluções de calibração em concentração de 0 a $45 \mu \mathrm{g} \mathrm{L}^{-1}$ para $\mathrm{Cu}$ e de 0 a $60 \mu \mathrm{g} \mathrm{L}^{-1}$ para $\mathrm{Pb}$, no próprio extrator, junto com a quantidade otimizada de modificador.

Tabela 3. Programa de aquecimento para a determinação de $\mathrm{Pb}$.

\begin{tabular}{|c|c|c|c|c|c|}
\hline Etapas & $\begin{array}{c}\text { Temperatura } \\
\left({ }^{\circ} \mathrm{C}\right)\end{array}$ & $\begin{array}{l}\text { Tempo } \\
\text { (s) }\end{array}$ & $\begin{array}{l}\text { Fluxo Gás } \\
\left(\mathrm{L} \min ^{-1}\right)\end{array}$ & $\begin{array}{l}\text { Tipo } \\
\text { Gás }\end{array}$ & $\begin{array}{c}\text { Comando } \\
\text { Leitura }\end{array}$ \\
\hline 1 & 300 & 30 & 3,0 & argônio & não \\
\hline 2 & 300 & 60 & 3,0 & argônio & não \\
\hline 3 & $*$ & 10 & 3,0 & argônio & não \\
\hline 4 & $*$ & 10 & 3,0 & argônio & não \\
\hline 5 & $*$ & 2 & 0,0 & argônio & não \\
\hline 6 & $* *$ & 1 & 0,0 & argônio & sim \\
\hline 7 & $* *$ & 3 & 0,0 & argônio & sim \\
\hline 8 & $* *$ & 2 & 3,0 & argônio & não \\
\hline 9 & 40 & 20 & 3,0 & argônio & não \\
\hline$* 1000^{\circ}$ & $\mathrm{C}$ e $* * 23$ & $0^{\circ} \mathrm{C}$ & fração 1 & & \\
\hline$* 1200^{\circ}$ & $\mathrm{C}$ e $* * 260$ & $0^{\circ} \mathrm{C}$ & fração 2 & & \\
\hline * $700^{\circ} \mathrm{C}$ & $\mathrm{C}$ e $* * 230$ & $0^{\circ} \mathrm{C}$ & fração 3 & & \\
\hline$* 1500^{\circ} \mathrm{C}$ & $\mathrm{C}$ e $* * 260$ & $0^{\circ} \mathrm{C}$ & fração 4 & & \\
\hline$* 1100^{\circ}$ & $\mathrm{C}$ e $* * 220$ & $0^{\circ} \mathrm{C}$ & fração 5 & & \\
\hline
\end{tabular}


(a)

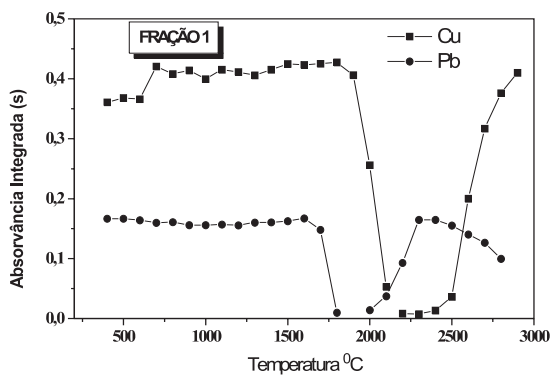

(b)

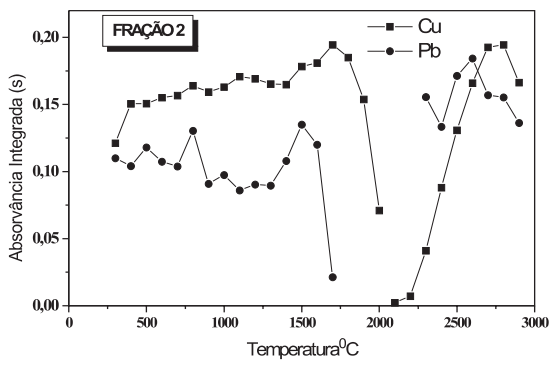

(c)

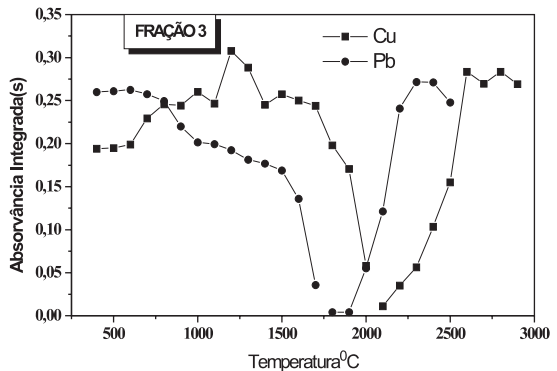

(d)

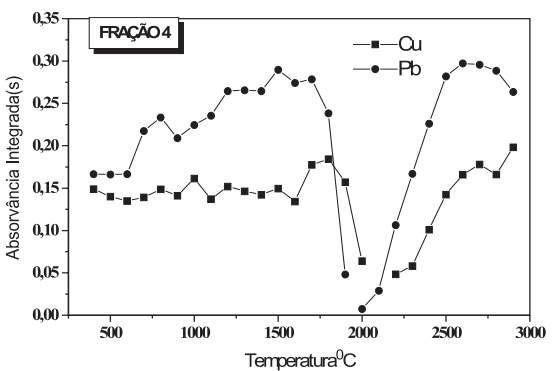

(e)

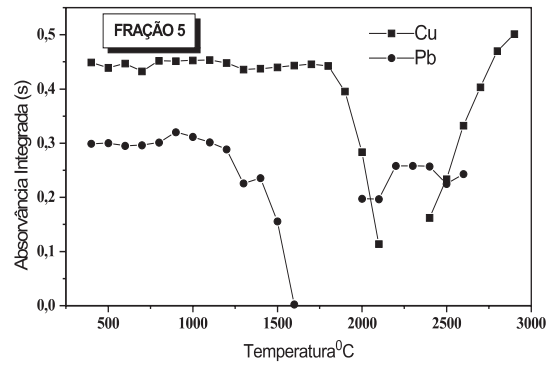

Figura 3. Curvas de pirólise e atomização: Para todas as otimizações foram injetados $15 \mu L$ da fração e $5 \mu L$ de modificador. As diluições, quando necessárias, foram feitas no próprio extrator.

(a) Fração 1 - adicionada de $60 \mu \mathrm{gL}^{-1}$ das respectivas espécies de interesse.

(b) Fração 2 - diluída duas vezes.

(c) Fração 3 - adicionada de $60 \mathrm{\mu gL}^{-1}$ de $\mathrm{Cu}$; para $\mathrm{Pb}$ diluída cinqüenta vezes.

(d) Fração 4 - adicionada $50 \mu \mathrm{gL}^{-1}$ de $\mathrm{Cu}$; para $\mathrm{Pb}$ diluída cinco vezes.

(e) Fração 5 - para $C u$ diluída cinco vezes e para $\mathrm{Pb}$ dez vezes.
Tabela 4. Otimização do uso de modificador químico Pd$\mathrm{Mg}\left(\mathrm{NO}_{3}\right)_{2}$ por fração de $\mathrm{Cu}$ e $\mathrm{Pb}$.

\begin{tabular}{ccc}
\hline Fração & $\begin{array}{c}\text { Quantidade de } \\
\text { modificador }(\mu \mathrm{L})-\mathrm{Cu}\end{array}$ & $\begin{array}{c}\text { Quantidade de } \\
\text { modificador }(\mu \mathrm{L})-\mathrm{Pb}\end{array}$ \\
\hline 1 & 10 & 9 \\
2 & 8 & 8 \\
3 & 6 & 3 \\
4 & zero & 2 \\
5 & zero & 3 \\
\hline
\end{tabular}

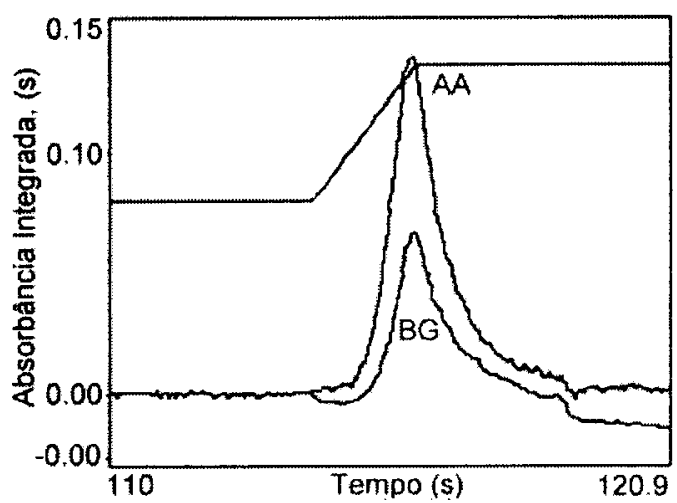

Figura 4. Sinal analítico para Cu obtido através do método Tessier após as otimizações.

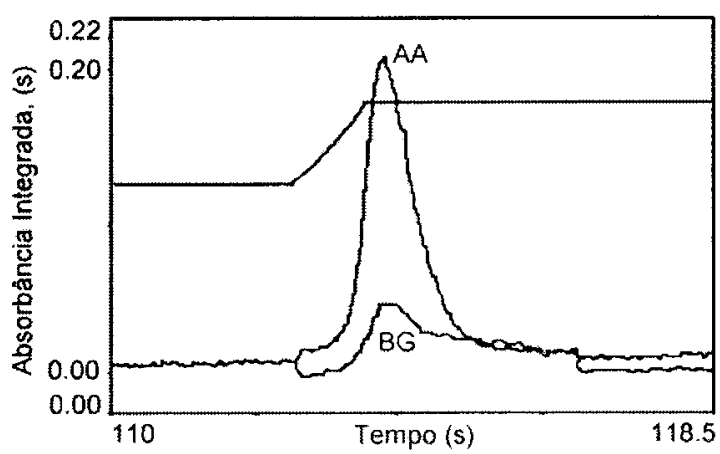

Figura 5. Sinal analítico para $\mathrm{Pb}$ obtido através do método Tessier após as otimizações.

No caso da calibração pelo método de adição de padrão, adicionou-se a uma mesma quantidade da fração, as mesmas concentrações da espécie de interesse que na curva de calibração, bem como a quantidade de modificador otimizada.

Quanto mais similares forem as inclinações, mais se terá corrigido o efeito interferente da matriz. No caso de serem menores que $5 \%$, significa que a espécie de interesse atomiza igualmente na matriz e nos padrões aquosos, não precisando utilizar a técnica de adição de padrão ${ }^{25}$. Neste estudo, fez-se a comparação das inclinações das curvas de calibração com os extratores e das curvas com adição de padrão. Conforme os resultados apresentados na Tabela 5, para todas as frações foi necessário utilizar a calibração com adição de padrão, tendo em vista as diferenças serem superiores a $5 \%$.

Concentração de $\mathrm{Cu}$ e $\mathrm{Pb}$ para as cinco frações nos dez pontos de amostragem do sedimento do Rio Tubarão.

A Tabela 6 apresenta os valores determinados para $\mathrm{Cu}$ e $\mathrm{Pb}$ nas cinco frações de cada ponto de amostragem. Os resul- 
Tabela 5. Inclinações das curvas de calibração $s\left(\mu g \mathrm{~L}^{-1}\right)^{-1}$ e valores dos coeficientes de correlação $(\mathrm{r}) \mathrm{para} \mathrm{Cu}$ e $\mathrm{Pb}$.

\begin{tabular}{|c|c|c|c|c|c|c|}
\hline $\begin{array}{c}\text { Espécies } \\
\text { de interesse }\end{array}$ & $\begin{array}{c}\text { Curva de } \\
\text { Calibração }\end{array}$ & Fração 1 & Fração 2 & Fração 3 & Fração 4 & Fração 5 \\
\hline \multirow{2}{*}{$\mathrm{Cu}$} & $\begin{array}{l}\text { Sem adição } \\
\text { de padrão }\end{array}$ & $\begin{array}{l}0,00231 \cdot \mathrm{C} \\
\mathrm{r}=0,9998\end{array}$ & $\begin{array}{l}0,00292 \cdot \mathrm{C} \\
\mathrm{r}=0,9989\end{array}$ & $\begin{array}{l}0,00360 \cdot \mathrm{C} \\
\mathrm{r}=0,9998\end{array}$ & $\begin{array}{c}0,00377 \cdot \mathrm{C} \\
\mathrm{r}=0,9960\end{array}$ & $\begin{array}{c}0,00615 . \mathrm{C} \\
\mathrm{r}=0,9999\end{array}$ \\
\hline & $\begin{array}{l}\text { Com adição } \\
\text { de padrão }\end{array}$ & $\begin{array}{l}0,00136 \cdot C \\
r=0,9984\end{array}$ & $\begin{array}{l}0,00128 . C \\
r=0,9935\end{array}$ & $\begin{array}{c}0,00246 . \mathrm{C} \\
\mathrm{r}=0,9983\end{array}$ & $\begin{array}{c}0,00208 . \mathrm{C} \\
\mathrm{r}=0,9988\end{array}$ & $\begin{array}{l}0,00182 . C \\
r=0,9991\end{array}$ \\
\hline \multirow{2}{*}{$\mathrm{Pb}$} & $\begin{array}{l}\text { Sem adição } \\
\text { de padrão }\end{array}$ & $\begin{array}{l}0,00252 \cdot \mathrm{C} \\
\mathrm{r}=0,9997\end{array}$ & $\begin{array}{l}0,00166 \cdot \mathrm{C} \\
\mathrm{r}=0,9998\end{array}$ & $\begin{array}{l}0,00141 \cdot \mathrm{C} \\
\mathrm{r}=0,9982\end{array}$ & $\begin{array}{l}0,00383 \cdot \mathrm{C} \\
\mathrm{r}=0,9993\end{array}$ & $\begin{array}{l}0,00325 \cdot \mathrm{C} \\
\mathrm{r}=0,9999\end{array}$ \\
\hline & $\begin{array}{l}\text { Com adição } \\
\text { de padrão }\end{array}$ & $\begin{array}{l}0,00101 \cdot C \\
r=0,9934\end{array}$ & $\begin{array}{l}0,00086 \cdot C \\
r=0,9996\end{array}$ & $\begin{array}{l}0,00070 \cdot \mathrm{C} \\
\mathrm{r}=0,9965\end{array}$ & $\begin{array}{c}0,00131 . \mathrm{C} \\
\mathrm{r}=0,9968\end{array}$ & $\begin{array}{l}0,00156 \cdot C \\
r=0,9955\end{array}$ \\
\hline
\end{tabular}

Tabela 6. Resultados obtidos para a concentração $\left(\mathrm{mg} \mathrm{kg}^{-1}\right)$ de $\mathrm{Cu}$ e $\mathrm{Pb}$ no sedimento do Rio Tubarão pelo método Tessier nos dez pontos de amostragem $(n=3)$.

\begin{tabular}{|c|c|c|c|c|c|c|c|}
\hline $\begin{array}{c}\text { Pontos de } \\
\text { Amostragem }\end{array}$ & Fração & $\mathrm{Cu}$ & $\mathrm{Pb}$ & $\begin{array}{r}\text { Pontos de } \\
\text { Amostragem }\end{array}$ & Fração & $\mathrm{Cu}$ & $\mathrm{Pb}$ \\
\hline & 1 & 0,08 & $* \mathrm{ND}$ & \multirow{6}{*}{$\begin{array}{c}6 \\
\text { Próximo da cidade } \\
\text { de Orleans }\end{array}$} & 1 & 0,37 & 0,11 \\
\hline 1 & 2 & 0,21 & 0,16 & & 2 & 0,31 & 0,84 \\
\hline Nascente (1) & 3 & 2,56 & 2,96 & & 3 & 1,83 & 4.89 \\
\hline do Rio Tubarão & 4 & 7,48 & 10,80 & & 4 & 3,50 & 14,87 \\
\hline \multirow{2}{*}{ Rio Bonito } & 5 & 49,70 & 30,00 & & 5 & 52,80 & 107,30 \\
\hline & total & 60,03 & 43,92 & & total & 58,80 & 128,01 \\
\hline \multirow{6}{*}{$\begin{array}{c}2 \\
\text { Nascente (2) } \\
\text { do Rio Tubarão } \\
\text { Rio Rocinha }\end{array}$} & 1 & 0,14 & 0,03 & \multirow{6}{*}{$\begin{array}{c}7 \\
\text { Após junção do } \\
\text { Rio Palmeiras }\end{array}$} & 1 & 0,28 & 0,09 \\
\hline & 2 & 0,36 & 0,46 & & 2 & 0,17 & 0,76 \\
\hline & 3 & 1,13 & 34,38 & & 3 & 0,36 & 46,44 \\
\hline & 4 & 14,40 & 34,40 & & 4 & 0,61 & 38,04 \\
\hline & 5 & 52,58 & 64,90 & & 5 & 40,46 & 116,5 \\
\hline & total & 68,61 & 134,17 & & total & 41,88 & 201,83 \\
\hline \multirow{6}{*}{$\begin{array}{c}3 \\
\text { Região de minera- } \\
\text { ção(1) }\end{array}$} & 1 & 0,33 & 0,06 & \multirow{6}{*}{$\begin{array}{c}8 \\
\text { Após junção do } \\
\text { Rio Braço do Norte }\end{array}$} & 1 & 0,24 & 0,13 \\
\hline & 2 & 0,18 & 0,41 & & 2 & 0,24 & 1,50 \\
\hline & 3 & 0,59 & 8,30 & & 3 & 3,81 & 15,46 \\
\hline & 4 & 4,83 & 31,46 & & 4 & 16,37 & 10,10 \\
\hline & 5 & 39,60 & 65,50 & & 5 & 48,05 & 55,40 \\
\hline & total & 45,53 & 105,73 & & total & 68,71 & 82,50 \\
\hline \multirow{6}{*}{$\begin{array}{c}4 \\
\begin{array}{c}\text { Região de minera- } \\
\text { ção(2) }\end{array}\end{array}$} & 1 & 0,14 & $* \mathrm{ND}$ & \multirow{6}{*}{$\begin{array}{c}9 \\
\text { Antes da cidade } \\
\text { de Tubarão }\end{array}$} & 1 & 0,15 & 0,04 \\
\hline & 2 & 0,09 & 0,10 & & 2 & 0,19 & 0,61 \\
\hline & 3 & 0,15 & 1,50 & & 3 & 1,95 & 9,12 \\
\hline & 4 & 1,03 & 8,40 & & 4 & 14,84 & 5,96 \\
\hline & 5 & 27,50 & 14,01 & & 5 & 47,90 & 42,40 \\
\hline & total & 28,91 & 24,01 & & total & 65,03 & 58,03 \\
\hline \multirow{6}{*}{$\begin{array}{c}5 \\
\text { Região de mineração, } \\
\text { cidade de Lauro } \\
\text { Müller }\end{array}$} & 1 & 3,21 & $* \mathrm{ND}$ & \multirow{6}{*}{$\begin{array}{c}10 \\
\text { Após junção do Rio } \\
\text { Capivari }\end{array}$} & 1 & 0,19 & 0,21 \\
\hline & 2 & 0,16 & 0,13 & & 2 & 0,24 & 2,26 \\
\hline & 3 & 0,75 & 0,22 & & 3 & 2,77 & 29,00 \\
\hline & 4 & 1,09 & 8,70 & & 4 & 16,90 & 14,30 \\
\hline & 5 & 24,30 & 97,90 & & 5 & 36,13 & 50,90 \\
\hline & total & 29,51 & 106,95 & & total & 56,23 & 96,67 \\
\hline
\end{tabular}

tados obtidos em cada fração, estão relacionados com as diferentes formas em que os metais podem estar associados ao sedimento. Neste sentido, os metais extraídos na Fração 1 (acetato de sódio, $\mathrm{pH} 8,2$ ) correspondem àqueles adsorvidos fracamente, em particular aos retidos na superfície do sedimento com uma fraca interação eletrostática. As trocas na composição iônica da água produzem uma grande influência no processo de adsorção-desorção. Na Fração 2 (acetato de sódio/ácido acético, pH 5), são extraídos os metais ligados a carbonatos. Os metais presentes na Fração 3 (cloreto de hidroxilamônio em $25 \% \mathrm{v} / \mathrm{v}$ de ácido acético) são aqueles associados a óxidos de ferro e manganês. Estes podem estar no sedimento como aglomerantes entre as partículas, ou recobrindo-as. Deste modo, apresentam uma grande superfície para adsorver metais traço. A redução do $\mathrm{Fe}^{3+}$ e do $\mathrm{Mn}^{4+}$ e sua consequiente dissolução liberam os metais adsorvidos. Na
Fração 4 (peróxido de hidrogênio $30 \%, \mathrm{pH}$ 2) têm-se os metais associados à matéria orgânica e sulfeto. Diferentes formas de matéria orgânica, como detritos, organismos vivos e coberturas de partículas, podem conter metais traço através de processos de sorção, complexação ou de bioacumulação. A oxidação desta fase pode liberar os metais ${ }^{16}$.

A Fração 5, residual ou inerte, contém minerais primários e secundários, os quais podem reter metais traço em sua estrutura cristalina, oriundos do substrato geológico natural. Não se espera que estes sejam liberados em um espaço de tempo razoável nas condições normais da natureza. Os metais desta fração são quimicamente estáveis e biologicamente inativos. A preparação desta fração residual para a análise foi feita utilizando-se a digestão ácida em microondas, embora tenham sido observadas também algumas publicações que preparam esta fração mediante o uso de suspensões ${ }^{26}$. 


\section{DISCUSSÃO}

Ao serem demarcados os pontos 1 e 2 próximos às nascentes, era esperado que os valores determinados para as espécies de interesse apresentassem uma concentração, chamada de natural (ou background $)^{27}$, ou seja, que a faixa de concentração servisse como referência para a comparação com os outros locais amostrados. Entretanto, foi observado no ponto 2, para as frações (1 a 4), conforme a Tabela 6 , em especial para o $\mathrm{Pb}$, que $51,6 \%$ do total encontram-se nas formas consideradas lábeis ou não inertes, e destes, predominando com 51,2 \% as formas associadas das frações (3 e 4). Em relação ao $\mathrm{Cu}, 21,0 \%$ encontra-se na fração (4). $\mathrm{A}$ presença de $\mathrm{Pb}$ deve estar associada às atividades de mineração de argila nas encostas acima deste ponto de coleta, na estrada da Serra do Rio do Rastro que expõe diversas formações geológicas. É possível a contaminação por arraste das partículas mais finas ao leito do rio, fato que merece ser melhor investigado nas camadas mais superficiais do sedimento.

Entre as camadas expostas estão a Itararé e a Ponte Alta, ambas com teores de matéria orgânica e possibilidades de formação de piritas $\left(\mathrm{FeS}_{2}\right)$ que se oxidam por exposição, liberando metais.

A oxidação da pirita que também ocorre associada ao carvão, quando exposta ao ar e à umidade, se oxida gerando $\mathrm{H}_{2} \mathrm{SO}_{4}$ e compostos de $\mathrm{Fe}$ que acabam sendo, de alguma forma, carregados até os cursos d'água. O ácido formado nesta oxidação dissolve os metais associados ao mineral e possibilita a sua ocorrência em altas concentrações ${ }^{28}$.

Os pontos 3, 4 e 5 correspondem a locais de coleta influenciados sobretudo por áreas de mineração. Destaca-se que há presença de $\mathrm{Cu}$ e $\mathrm{Pb}$, principalmente nas formas ligadas a óxidos e à matéria orgânica. Entretanto, os valores encontrados nas fases móveis foram menores em relação aos valores encontrados nos pontos 1 e 2, considerados brancos. Tendo em vista a diminuição do $\mathrm{pH}$ da água de 6,5 nas nascentes, para em média 3,1 nestes pontos, e considerando a solubilidade dos metais em meio ácido e alterações no equilíbrio redox do meio, as concentrações obtidas para as frações (3 e 4) diminuíram.

O ponto 6 , demarcado após a cidade de Orleans, ainda apresenta indicação de metais associados a óxidos, destacando-se a espécie $\mathrm{Pb}$, possivelmente pela pouca distância (cerca de $12 \mathrm{~km}$ da principal região da exploração do carvão), bem como a presença de metais associados à matéria orgânica e sulfeto, contribuição de esgotos domésticos e outras fontes, tais como efluentes das indústrias madeireiras e disposição inadequada de resíduos sólidos 29

O ponto 7 tem forte acréscimo, sobretudo, na concentração de $\mathrm{Pb}$ sedimentado, observando-se os valores determinados nas frações (3 e 4), que pode ser por adsorção em matéria orgânica ou precipitação de sulfetos. A própria liberação do $\mathrm{Pb}$ também torna-se difícil devido à imediata formação de sulfato insolú$\mathrm{vel}^{30}$. A troca de $\mathrm{Pb}$ entre o sedimento e a solução sobrenadante deve obedecer, neste caso, aos produtos de solubilidade do sulfato em meio oxidante e do sulfeto em meio redutor, dificultando, assim, sua presença maior no meio líquido. Entretanto, pela influência na saúde humana, é necessária uma preocupação direta sobre possibilidades de solubilização. Essa região apresenta uma maior deposição de $\mathrm{Pb}$ uma vez que o Rio Palmeiras também passa por região de mineração de carvão ${ }^{31,32}$. No ponto 8 , para $\mathrm{Pb}$, foram obtidos valores mais significativos nas frações (3 e 4), enquanto que para $\mathrm{Cu}$ obteve-se na fração (4). Estes valores estão relacionados, possivelmente, com a presença marcante das diferentes atividades agropecuárias e contribuição da confluência do Rio Braço do Norte, que favorece a precipitação dos metais pelo aumento do $\mathrm{pH}$.

No ponto 9, praticamente mantém-se a presença dos metais ligados a óxidos e à matéria orgânica.

No ponto 10 , acentua-se pouco a concentração principalmente de $\mathrm{Pb}$ nas frações (3 e 4), e mantém-se a presença de $\mathrm{Cu}$ nas mesmas frações. Foram observadas poucas alterações, considerando ser um local de coleta, onde já recebeu a contribuição do Rio Capivari e do canal da empresa que gera energia elétrica a partir da queima do carvão.

Para todos os pontos, as frações (1 e 2) apresentaram valores relativamente baixos e até mesmo não detectados. Observando-se porém os pontos 1 e 2 , localizados nas nascentes, onde o pH da água é praticamente neutro, a concentração de metais nas formas facilmente trocáveis e ligados a carbonatos sugere não haver fases lábeis nesse sedimento. Para os demais pontos, baixos valores determinados ou não detectados, como $\mathrm{Pb}$ nos pontos 4 e 5, alertaram-nos no sentido de que predominam, nestes locais, valores muito baixos de $\mathrm{pH}$, sobretudo nos pontos 3 a 5, aumentando muito pouco até o ponto $10(\mathrm{pH}$ $5,6)$. Isto é preocupante, pois, considerando a solubilidade dos metais em meio ácido, os sedimentos poderiam contribuir para a água com concentrações de metais, causando assim um efeito de recontaminação do meio aquático e, por conseqüência, afetar às comunidades locais e outras mais distantes que podem sofrer os efeitos do transporte e difusão deste tipo de poluente.

Para efeito de comparação, foi avaliado o somatório das concentrações das frações, obtidas no processo de extração seqüencial, com o resultado das concentrações determinadas pela digestão total do sedimento. Conforme pode-se observar na Tabela 7, não houve perdas significativas nas etapas de extração, propiciando a vantagem da verificação das diferentes associações em que os metais se encontram.

Nas Figuras 6 e 7, observa-se a porcentagem das frações em cada ponto de amostragem, para $\mathrm{Cu}$ e $\mathrm{Pb}$, respectivamente. Para o $\mathrm{Cu}$, os pontos de amostragem 4 e 7 foram os que apresentaram menor porcentagem de frações lábeis, correspondendo a $4,89 \%$ e $3,38 \%$, respectivamente. Os demais pontos oscilaram entre $10,22 \%$ e $36,20 \%$. O ponto 4 faz parte da

Tabela 7. Concentração $\left(\mathrm{mg} \mathrm{kg}^{-1}\right)$ de $\mathrm{Cu}$ e $\mathrm{Pb}$, determinadas no sedimento do Rio Tubarão obtidas pela digestão total.

\begin{tabular}{ccc}
\hline $\begin{array}{c}\text { Pontos de } \\
\text { amostragem }\end{array}$ & $\mathbf{C u}$ & $\mathbf{P b}$ \\
\hline 1 & 72,20 & $(\mathrm{RSD}<10,0 \%)$ \\
2 & 71,68 & 46,30 \\
3 & 53,32 & 141,35 \\
4 & 28,74 & 116,75 \\
5 & 32,34 & 28,68 \\
6 & 54,97 & 122,51 \\
7 & 49,54 & 123,20 \\
8 & 70,40 & 232,96 \\
9 & 65,10 & 91,10 \\
10 & 58,50 & 71,43 \\
\end{tabular}

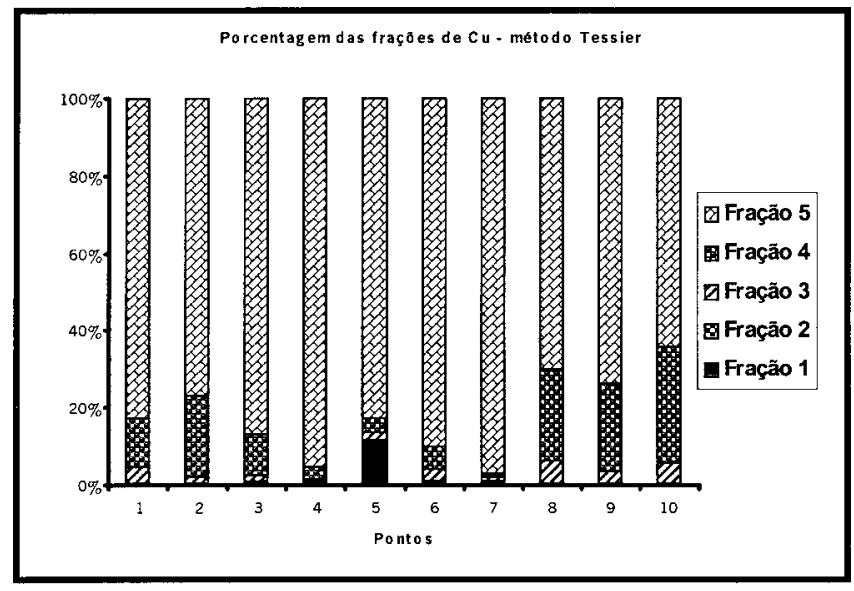

Figura 6. Porcentagem das Frações de $\mathrm{Cu}$ nos dez pontos de amostragem, onde: Frações 1 a 4 (lábeis), e Fração 5 (residual ou inerte). 


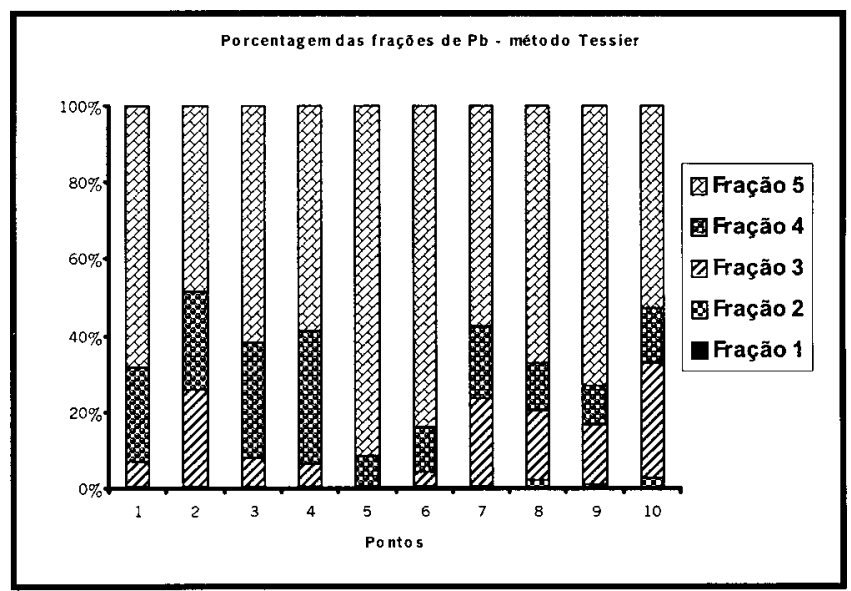

Figura 7. Porcentagem das Frações de $\mathrm{Pb}$ nos dez pontos de amostragem, onde: Frações 1 a 4 (lábeis), e Fração 5 (residual ou inerte).

região crítica de mineração com $\mathrm{pH}$ em torno de 3,0. E o ponto 7 tem a confluência do Rio Palmeiras que também apresenta rejeitos de mineração de carvão.

$\mathrm{O}$ ponto 5 foi o que apresentou menor porcentagem de frações lábeis (aquelas mais facilmente trocáveis), em relação ao $\mathrm{Pb}$. Os demais pontos oscilaram entre $16,17 \%$ a $51,62 \%$.

Embora outros parâmetros físico- químicos possam influenciar nas diferentes formas de concentrações de metais, acreditase que os menores valores de frações lábeis determinadas no sedimento sejam pelo fato da solubilidade dos metais em meio ácido.

\section{Características Analíticas do Método}

\section{Sensibilidade}

Para poder avaliar a aplicabilidade do método, é recomendado conhecer sua sensibilidade. Para tanto, foi estudada para cada fração a massa característica $\left(\mathrm{m}_{\mathrm{o}}\right)$, massa que produz uma absorbância de 0,0044 s, o limite de detecção(LD) e o limite de quantificação (LQ). Na Tabela 8, estão apresentados os resultados.
$\mathrm{A} \mathrm{m}_{0}$ foi obtida para $\mathrm{Cu}$ e $\mathrm{Pb}$ nas cinco frações, fazendose leituras em diferentes concentrações, utilizando-se volumes de $25 \mu \mathrm{L}$ dos padrões diluídos no próprio extrator. Os limites de detecção e quantificação para os elementos, no método em estudo, foram calculados considerando $L D=3 \sigma / \mathrm{a}$ e $\mathrm{LQ}=10 \sigma / \mathrm{a}$, onde "a" é a inclinação da curva de calibração, " $\sigma$ " corresponde ao desvio padrão (em absorvância) calculado a partir de dez leituras do branco da amostra. Os números 3 e 10 correspondem a um valor estatístico eleito de acordo com o nível de probabilidade de $99,7 \%$. Os valores apresentados para o LD e LQ foram determinados, considerando as diluições quando necessárias, assim como o emprego de $1 \mathrm{~g}$ de amostra para as extrações.

\section{Precisão do Método}

O estudo da precisão foi realizado a partir da leitura de três séries de amostra com diferentes concentrações de $\mathrm{Cu}$ ou $\mathrm{Pb}$ e a quantidade de modificador otimizado para cada fração. Cada série foi lida dez vezes e foi calculada a média das absorvâncias $(\bar{X})$, o desvio padrão $(\sigma)$ e o coeficiente de variação $(\mathrm{CV})$. Este último é calculado a partir da seguinte equação $C V=\sigma / X .100$. Os baixos valores do CV indicaram uma boa precisão.

\section{Exatidão do Método}

A exatidão foi avaliada a partir da recuperação analítica. As frações foram enriquecidas com diferentes concentrações de $\mathrm{Cu}$ e $\mathrm{Pb}$. Todas as contaminações foram efetuadas e processadas em triplicata. Na Tabela 9, estão reunidos os percentuais de recuperação obtidos para cada fração. São valores aceitáveis, sobretudo, considerando o caráter complexo da matriz.

\section{CONCLUSÃO}

Os metais considerados menos inertes são aqueles extraídos nas quatro primeiras frações. As formas associadas em que foram determinadas as maiores concentrações foram aquelas ligadas a óxidos de $\mathrm{Fe}$ e $\mathrm{Mn}$ e ligadas à matéria orgânica e sulfeto, que correspondem às frações 3 e 4, respectivamente.

Apesar das enumeradas vantagens para o processo de extrações seqüenciais, o seu emprego apresenta problemas na interpretação dos dados quando o objetivo é obter previsões corre-

Tabela 8. Valores obtidos para a sensibilidade do método Tessier.

\begin{tabular}{|c|c|c|c|c|c|c|}
\hline & $\begin{array}{c}\text { Espécies } \\
\text { de interesse }\end{array}$ & Fração 1 & Fração 2 & Fração 3 & Fração 4 & Fração 5 \\
\hline Massa & $\mathrm{Cu}$ & 35,75 & 34,27 & 37,40 & 23,40 & 27,00 \\
\hline $\begin{array}{c}\text { Característica } \\
\mathrm{m}_{\mathrm{o}}(\mathrm{pg})\end{array}$ & $\mathrm{Pb}$ & 43,75 & 66,00 & 78,00 & 23,30 & 33,75 \\
\hline Limite de & $\mathrm{Cu}$ & 10,16 & 4,08 & 133,60 & 7,40 & 11,37 \\
\hline $\begin{array}{l}\text { Detecção LD } \\
\left(\mu \mathrm{gg}^{-1}\right)\end{array}$ & $\mathrm{Pb}$ & 20,00 & 8,96 & 43,40 & 17,40 & 16,86 \\
\hline Limite de & $\mathrm{Cu}$ & 33,92 & 13,60 & 456,00 & 24,80 & 37,65 \\
\hline $\begin{array}{l}\text { Quantificação } \\
\text { LQ }\left(\mu \mathrm{g} \mathrm{kg}^{-1}\right)\end{array}$ & $\mathrm{Pb}$ & 66,72 & 27,76 & 144,60 & 58,40 & 56,08 \\
\hline
\end{tabular}

Tabela 9. Precisão (\%CV) e exatidão (\% de recuperação) para o método Tessier.

\begin{tabular}{ccccccc}
\hline & $\begin{array}{c}\text { Espécies } \\
\text { de interesse }\end{array}$ & Fração 1 & Fração 2 & Fração 3 & Fração 4 & Fração 5 \\
\hline Coeficiente de & $\mathrm{Cu}$ & $3,6-6,2-5,4$ & $7,3-2,8-5,6$ & $5,6-11,1-2,8$ & $3,0-3,8-4,9$ & $2,0-1,4-1,3$ \\
Variação $(\%)-\mathrm{CV}$ & $\mathrm{Pb}$ & $3,7-2,6-1,8$ & $3,4-3,3-1,5$ & $1,5-1,4-1,6$ & $1,8-2,9-2,5$ & $1,0-0,9-1,5$ \\
3 séries & & & & & & \\
\hline (\%) Recuperação & $\mathrm{Cu}$ & 93,5 & 99,2 & 100,2 & 102,6 & 98,5 \\
& $\mathrm{~Pb}$ & 111,00 & 101,27 & 99,22 & 100,68 & 99,90 \\
\hline
\end{tabular}


tas sobre os possíveis processos de mobilização dos elementos. Por isso, a seleção de um esquema de especiação adequado para cada problemática ambiental constitui, na atualidade, um dos temas fundamentais de estudo neste campo da especiação analítica. Faz-se necessário um estudo mais aprofundado para conhecer o comportamento dos metais no ambiente. Desta forma, é de fundamental importância a interdisciplinariedade para encontrar princípios gerais de informações e interpretação dos resultados.

Para o mesmo sedimento, está sendo estudada a aplicação do método protocolado pela BCR.

\section{AGRADECIMENTOS}

Agradecemos ao CNPq pela bolsa de recém-doutor concedida à Dra. Maria Bertilia Oss Giacomelli. E, em especial, à Dra. Haidi D. Fiedler por suas valiosas sugestões.

\section{REFERÊNCIAS}

1. Universidade do Sul de Santa Catarina - UNISUL e Secretaria de Estado de Desenvolvimento Urbano e Meio Ambiente. Diagnóstico dos recursos hídricos e organização dos agentes da bacia hidrográfica do Rio Tubarão-SC.,1998. 2.

2. Santa Catarina, Secretaria de Estado de Desenvolvimento Urbano e Meio Ambiente. Plano básico de desenvolvimento ecológico - econômico. Associação dos municípios da região de Laguna: AMUREL. 1994.

3. Marcomin, F.E.; Dissertação de Mestrado; Universidade Federal do Rio Grande do Sul - UFRGS, Porto Alegre, RS, 1996.

4. Alonso, M.C.B.; Tese de Doutoramento; Universidade de Santiago de Compostela - USC, Santiago de Compostela, Espanha, 1995.

5. Chantero, J.C.C.; Trabalho de Conclusão de Curso. Universidade de Santiago de Compostela -USC, Santiago de Compostela,Espanha, 1996.

6. Gunn, A. M, Winnard, D.A. ; Hundt, D.T.E. Metal Speciation: Theory, Analysis and Application; Ed.;James R. Kramer and Herbert E. Allen; U.S.A.,1988;p 261.

7. Wang, X. Q.; Thibodeaux, L. J.; Valsaraj, K. T.; Environ. Sci. Technol. 1991, 25, 1578.

8. Thoma, G. J.; Reible, D.D.; Valsaraj, K. T.; Environ. Sci. Technol. 1993, 27, 2412.

9. Scorzelli, I. B.; Fragomeni, A. L.; Torem, M.L.; Encontro Nacional de Tratamento de Minérios e Metarlugia Extrativa, São Pedro-SP, 1998, 255.

10. Horowitz A., A Primer on sediment - trace element chemistry, 2. ed., Lewis Publishers, 1991.

11. Jones B.; Bowser, C.; The mineralogy and related chemistry of lake sediments, in Lerman, A., ed., Lakes: Chemistry,
Geology, Physics, New York, Springer-Verlag, 1978, 179.

12. Förstner, U.; Chemicals Forms of Metal Enrichment in Recent Sediments. In Amstutz G. and others, eds., Ore Genesis, New York, Springer-Verlag, 1982, 191.

13. Horowitz, A.; Elrick, K.; Appl. Geochem. 1987, 2, 437.

14. Malins, D.; Environ. Sci. Technol., 1984, 18, 705.

15. Davidson, C. M.; Thomas, R. P.; Mcvey, S. E.; Perala, R.; Littlejohn, D.; Ure, A. M.; Anal. Chim. Acta. 1994 291, 277.

16. Tessier, A.; Campbell, P. G. C.; Bisson, M.; Anal. Chem. 1979, 51, 844 .

17. Meguellati, N.; Robbe D.; Marchandise P.; Astrucc M.; Proc. In. Conf. on Heavy Metals in the Environment, Heidelberg, 1983,1090.

18. European Commission. BCR information reference materials, 1997; 51.

19. Quevauviller, P.; Rauret, G.; Muntau, Ure, A. M.; Rubio, R.; López-Sánchez, J. F. H.; Fiedler, H. D.; Griepink, B.; Fresenius J. Anal. Chem. 1994, 349, 808.

20. Texeira, E.C.;Pestana, M.H.D.; Sanchez J.; Fernandes, I.; Environ. Technol. 1993, 15, 989.

21. Santos, E.; Dissertação de Mestrado. Universidade Federal de Santa Catarina - UFSC, Florianópolis, SC, 1992.

22. Santa Catarina, Secretaria Municipal de Agricultura/Empresa de Pesquisa Agropecuária e de Extensão RuralEPAGRI 1996. Plano municipal de desenvolvimento rural.

23. Fiedler, H.D.L.; Tese de Doutoramento, Universidade de Barcelona,Barcelona, Espanha,1995.

24. Slavin, W. ; Manning, D.C.; Carnrick,G.R.; At. Spectrosc. 1981, 2,137

25. Díaz ,M. I. G.; Tese de Doutoramento,Universidade de Huelva, Espanha,1997.

26. Bermejo-Barrera, P.; Alonso, B C.; Somoza, A. M.; Barrera, B. A.; J. Anal. Atom. Spectrom. 1994, 9, 469.

27. Jardim, W. F.; Rev. Bras. Tecnol. 1983, 14, 45.

28. Gothe, C. A. V.; Dissertação de Mestrado, Universidade Federal de Santa Catarina-UFSC, Florianópolis, SC, 1993.

29. Universidade do Sul de Santa Catarina. Diagnóstico dos recursos hídricos e organização dos agentes da bacia hidrográfica do Rio Tubarão- SC. Tubarão: Secretaria de Estado de Desenvolvimento Urbano e Meio Ambiente, 1998. 3.

30. Vogel, A. I.; Química Analítica Qualitativa ; Ed.; Mestre Jou, São Paulo, 1981; p 84

31. Santa Catarina, Secretaria do Estado de Desenvolvimento Urbano e Meio Ambiente. Bacias hidrográficas de Santa Catarina: diagnóstico geral. 1997; p.163.

32. Universidade do Sul de Santa Catarina-UNISUL e Instituto Nacional de Pesquisas Hidrovárias-INPH. Avaliação físico-química do sistema Lagunar Sul Catarinense. 1994. 